\title{
Pharmacist-Monks in the Tang Dynasty: A Group of Mahayana Buddhist Followers and their Contributions to Chinese Buddhism
}

\author{
Xican $\mathrm{Li}^{1}$ \\ ${ }^{1}$ School of Chinese Herbal Medicine, Guangzhou University of Chinese Medicine, Guangzhou, 510006, China. \\ Correspondence: Xican Li, School of Chinese Herbal Medicine, Guangzhou University of Chinese Medicine, \\ Guangzhou, 510006, China. Tel.: +86-20-3935-8076; Fax: +86-20-3889-2690
}

Received: June 8, 2016

Accepted: June 21, 2016

Available online: July 4, 2016

doi:10.11114/ijsss.v4i8.1714

URL: http://dx.doi.org/10.11114/ijsss.v4i8.1714

\begin{abstract}
Pharmacist-monks (yaoseng ${ }^{1}$ ), a group of Buddhist monks who devote themselves to the production of Chinese herbal medicines, have existed in China for over 1000 years, but are still poorly understood. To provide important insight into the special religious group, this study inspected Poetry of the Tang Dynasty and other historical data in Chinese ancient texts. The results suggest there were numerous pharmacist-monks in the Tang Dynasty. From the samvrti-satya viewpoint, they participated in the entire manufacturing process for Chinese herbal medicines, and sometimes directly carried out medical charity activity. Their contributions to Chinese Buddhism are summarized as: (i) to provide herbal medicines as a form of Buddhist charity, or to express compassionate ideals of Buddhism via direct medical charity; (ii) to provide food for devotees at Buddhist temples; and (iii) to beautify Buddhist temples. However, from the paramartha-satya viewpoint, these pharmacist-monks actually practiced six paramitas (i.e. dana, sila-vinaya, ksanti, virya, dhyana, and prajna) which are the main characteristics of mahayana Buddhism. Therefore, they are considered as mahayana followers. They lived laborious but happy, and were widely respected by the secular society. They inherited mahayanist tradition and accelerated the development of mahayana Buddhism in China.
\end{abstract}

Keywords: Pharmacist-monks, yaoseng, mahayana follower, Poetry of Tang Dynasty, six paramitas

\section{Introduction}

\subsection{Introduction to the Term "Yaoseng" and its Background}

In 2008, when a large earthquake struck Wenchuan, China, a group of pharmacist-monks (yaoseng ${ }^{1}$ ) was dispatched to tend to the injured. The group was from the famous Shaolin Buddhist Temple, and their charity was reported by several media outlets (Zhong, 2008). To most Chinese people, the term yaoseng is very strange and many are interested to know: How did they cultivate Chinese herbal medicines? What were their contributions to Chinese Buddhism? And were they mahayana followers or hinayana followers?

Yaoseng refers to a group of Buddhist monks who devote themselves to the production of Chinese herbal medicines. According to our textual analysis, this term first emerged in the Song Dynasty (960-1279 AD). A poet named Jin Junqing wrote a poem titled Visiting Yangfu Temple, in which he described a pharmacist-monk (yaoseng) sweeping the pine flower (Jin, 2015). This implies that pharmacist-monks emerged prior to the Song Dynasty.

As we know, Buddhism originated in ancient India and was introduced to China around the first century AD. In the early stage of Chinese Buddhism, many Buddhist monks from India or its neighboring countries were skilled in medicine. Their medical charity greatly promoted the establishment of Buddhism in China. These were called doctor-monks (yiseng ${ }^{2}$ ). The eminent monk An Shigao is considered to be the first doctor-monk in Chinese history (Figure 1) (Shi, 1992).

\footnotetext{
${ }^{1}$ Yaoseng, 药僧, 藥僧 in Chinese; ${ }^{2}$ Yiseng, 医僧, 醫僧 in Chinese.
} 


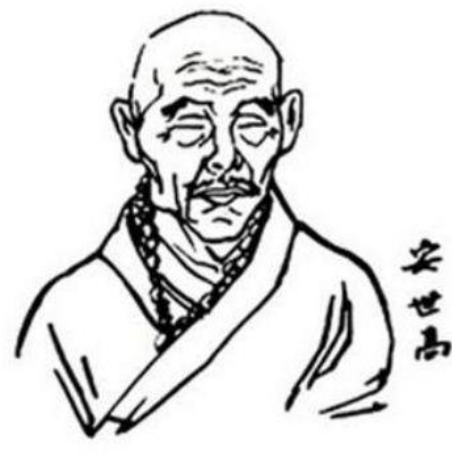

A

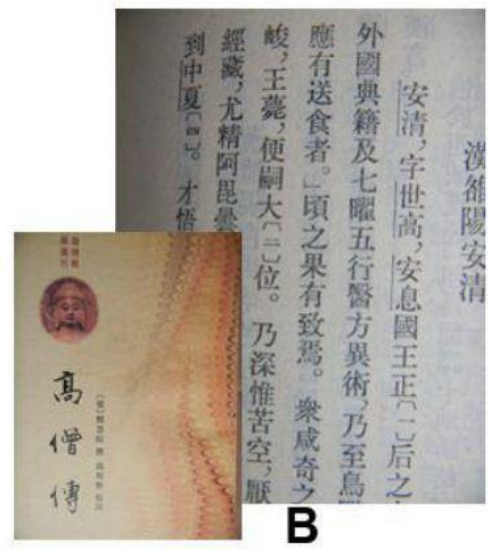

Figure 1. An Shigao (A); His Biography in Biographies of Eminent Monks (B)

(Figure B shows part of the page 4-8 from The Biography of Eminent Monks (Liang), published by Zhonghua Book Company, 1992, Beijing).

After the fourth century AD, Buddhism spread widely, and gradually became the most influential religion in China. As suggested by the previous study, there was interaction between medicine and religion (Harold, 2012). Thus, more and more Chinese local monks also took part in medical charity during this period. Of course, the word "medical" refers here to traditional Chinese medicine (TCM), including medicine and pharmaceuticals. Generally, the pharmaceutical aspect of TCM is also called Chinese herbal medicine. With the rapid development of Chinese Buddhism, some Buddhist monks may have specialized in the production of herbal medicines, and thus emerged a special group of pharmacist-monks (yaoseng). Undoubtedly, the emergence of pharmacist-monks may have been later than that of doctor-monks. However, it is very difficult to verify when doctor-monks first emerged in China. As we know, during the Tang Dynasty (618-907 AD), Chinese Buddhism reached its peak and many specialized pharmacist-monks were then engaged in the production of Chinese herbal medicines. Therefore, the study of pharmacist-monks in the Tang Dynasty may provide important insight into this religious group (i.e. pharmacist-monks) in ancient China.

\subsection{Main Historical Data for the Analysis}

The present study is based on the analysis of historical data in Chinese ancient texts. However, since pharmacist-monks usually lived in forests or mountains far from cities and villages, secular people could seldom contact and come to understand them. Therefore only three ancient texts relate to pharmacist-monks, The Old Book of Tang History, Biographies of Eminent Monks (Song), and Poetry of the Tang Dynasty.

The Old Book of Tang History is known as one of the Twenty-Four Histories in Chinese culture. As we know, these historical books recorded political affairs, and focused on the activities of emperors or ministers. Religious groups such as pharmacist-monks are seldom mentioned. Our literature search indicated only two records concerning pharmacist-monks in The Old Book of Tang History. A biography in Vol. 60 records that a pharmacist-monk named Seng Datong was executed by Emperor Tangmuzong, because his false drugs had caused the death of Emperor Tangxianzong (Liu, 2015a). Surprisingly, in Vol. 184 of this book, Emperor Tangxianzong's death is attributed to a political struggle in the palace (Liu, 2015b). This suggests that political historical records are sometimes conflicting and unreliable. In the Buddhist text Biographies of Eminent Monks (Song), however, we find several records of doctor-monks such as Shi Falang (Zan, 1987a), Shi Sengjia (Zan, 1987b), and Shi Daibin (Zan, 1987c), but no record of pharmacist-monks.

Fortunately, many Buddhist poets who enjoyed contact with (pharmacist) monks faithfully recorded their observations in poems. These records have not been disturbed by other factors and are collected in the ancient text Poetry of the Tang Dynasty (Figure 2A). It must be emphasized that there are about 50,000 poems in Poetry of the Tang Dynasty, and the inspection of these poems is difficult. In short, Poetry of the Tang Dynasty may be the best (or even sole) approach for us to understand the pharmacist-monks of ancient China.

The present study tries to investigate pharmacist-monks in the Tang Dynasty based on the ancient text Poetry of the Tang Dynasty, and further discusses their mahayana characteristics and contributions to Chinese Buddhism. 


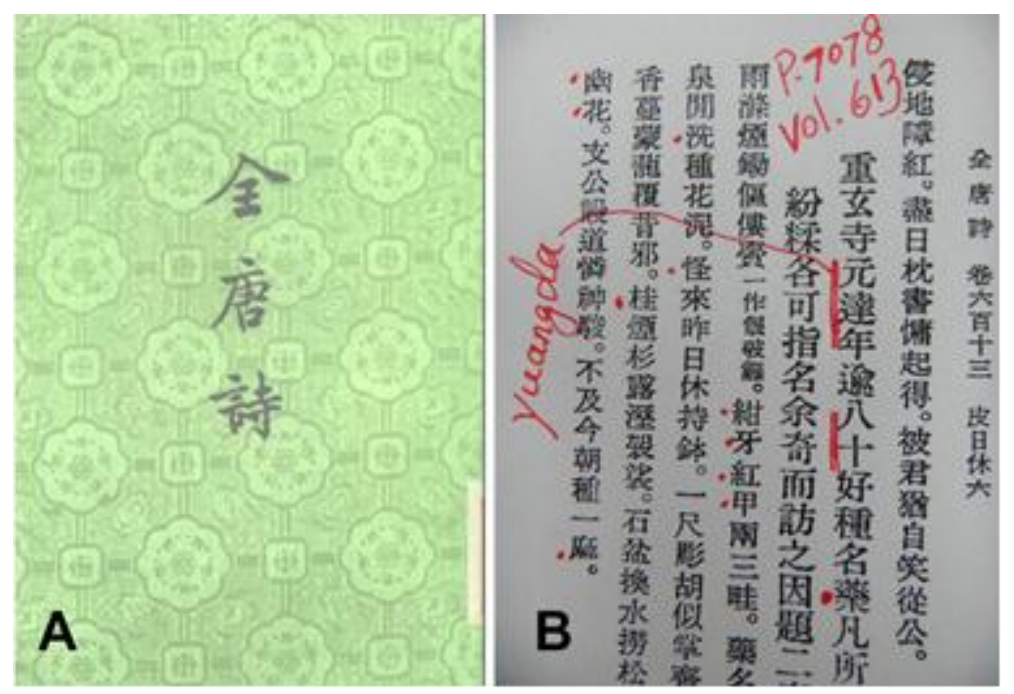

Figure 2. Poetry of the Tang Dynasty (A); description of Yuanda (Pi, 1960) (B)

\subsection{Production by Pharmacist-Monks (Samvrti-Satya)}

The mission of pharmacist-monks was obviously to produce Chinese herbal medicines. Our analysis noted that pharmacist-monks participated in the entire manufacturing process for herbal medicines, including planting, collection, sun-drying, fragmentation, and storage.

It has been documented that at some Buddhist temples, pharmacist-monks cultivated medicinal rhizomes (or fungi) in the so-called zhizhutian (farmland used for cultivation of Chinese herbal medicines linzhi and baizhu) (Bai, 1960a). Besides linzhi and baizhu, there were 32 types of plant-based Chinese herbal medicines cultivated by pharmacist-monks (Bai,1960a; Bai,1960b; Bai,1960c; Bai,1960d; Bai,1960e; Bai,1960f; Cao S, 1960a; Cao Z, 1960; Cen, 1960b; Ding,1960; Du, 1960a; Du, 1960b; Duan, 1960; Gu, 1960; Guan, 1960; Han Y, 1960; Huangfu R,1960; Huangfu Z, 1960; Jiao, 1960a; Jiao, 1960b; Li B, 1960; Li DY, 1960; Li X, 1960; Li XY, 1960; Li YX, 1960; Liu J, 1960; Liu S, 1960a; Liu S, 1960a; Liu, YS, 1960; Lu, 1960; Pei, 1960; Pi, 1960a; Pi, 1960b; Qi, 1960; Quan, 1960; Si, 1960; Sun, 1960; Wang J, 1960a; Wang J, 1960b; Wang J, 1960c; Wei, 1960; Wu, 1960; Xiang, 1960; Xu H, 1960; Xu Y, 1960a; Xu Y, 1960b; Xue, 1960a; Xue, 1960b; Yuan, 1960a; Yuan, 1960b; Zhang J,1960; Zhao, 1960; Zhou H, 1960; Zhou HL, 1960).

When these medicinal plants matured, the pharmacist-monks would begin to harvest them. Usually, they would hang a bag in the tree to collect the fruit, leaves, or flowers. The poet Liu Shan observed the collection of zhishi from a Citrus aurantium L. tree at Qushui Temple (Liu S, 1960b). Besides these cultivated medicinal plants, wild plants were sometimes needed to make up a prescription. In this case, pharmacist-monks had to search for them around the mountain (Jiao, 1960c). Such searching and collection was described as difficult and dangerous by the poet Li Duan (Li D, 1960).

In general, the collected herbs were fresh, thus they would be sun-dried. In some large temples, the pharmacist-monks might put them on a big stone called a shaiyaotai for sun-drying (Bai, 1960a). At small temples, however the monks could only pile up the medicines against an outer wall for drying (Ding, 1960).

Subsequently, some dried ingredients, especially rhizomes and fruits, needed to be fragmented. The pharmacist-monks might use knife to cut them, then smash them into pieces or powder with a special tool called a yaochu in a special vessel called a yaojiu (Figure 3) (Bai, 1960g; Jia, 1960).

Finally, the pharmacist-monks could use the fragmented medicines to manufacture various drugs, such as pills, ointments, and so on. The drugs were then stored for application in the future. Some precious pills, however, were deposited in secret holes (Yu, 1960) or Buddhist niches (Wang W, 1960) (Figure 4), and were guarded by monks (Yao, 1960). The manufactured pills were small but believed to be effective in treatment (Xu ZY, 1960).

Undoubtedly, all records of cultivation activities were based on the secular observations of the poets. It is called samvrti-satya (merely conventional truth) in Chinese Buddhism. However, from the viewpoint of paramartha-satya (the absolute truth, as opposed to merely conventional truth), they were practicing and fulfilling the six paramitas of mahayana Buddhism. 


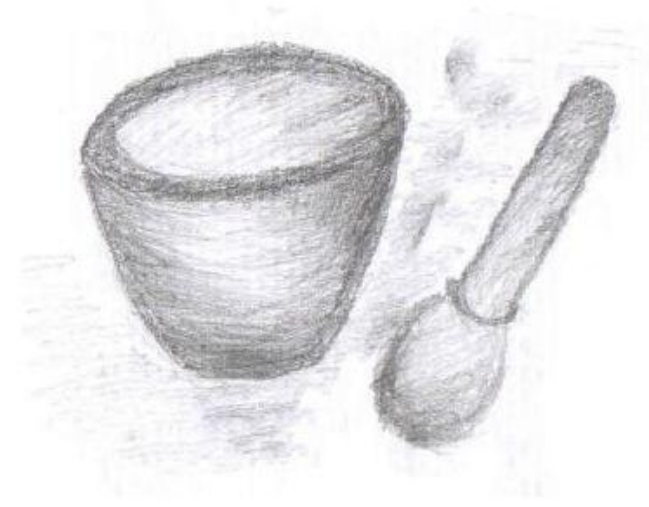

Figure 3. Yaochu (right) for smashing Chinese herbal medicines; yaojiu vessel (left) (Drawn by Qian Jiang)

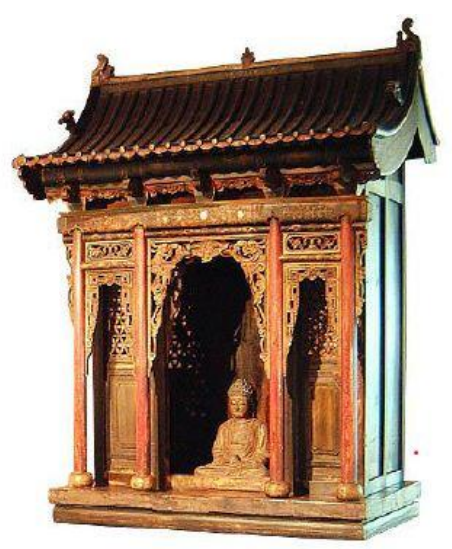

Figure 4. A Buddhist Niche and a Buddha Statue

(Contributed by http://www.liaotuo.org/remen/fokan.html)

\subsection{Mahayana Characteristics of the Pharmacist-Monks (Paramartha-Satya)}

In Chinese Buddhism system, the Buddhism can be divided as two major branches, i.e. mahayana Buddhism and hinayana Buddhism. The main difference between them is so-called six paramitas (Sanskrit, meaning "other-shore-reached"), including dana, sila-vinaya, ksanti, virya, dhyana, and prajna (Chen B, 1993a). A Buddhist following six paramitas is called mahayana follower.

\subsubsection{Dana Paramita (Contributions to Chinese Buddhism of Pharmacist-Monks)}

Dana paramita (Sanskrit) generally means "alms giving", it is the practice of cultivating generosity. It can take the form of giving to an individual in distress or need, and usually classified into three types: property dana, dharma dana, and fearlessness dana (Chen B, 1993a). The records by poets suggested that pharmacist-monks were involved in the three dana paramitas. As discussed above, pharmacist-monks produced various Chinese herbal medicines. These herbal medicines were of course firstly used for the treatment of various diseases. It is well documented that in the Tang Dynasty, Buddhist temples usually set up a medical charity department called a beitianfang, where herbal medicines were consumed as part of treatment (Zhang ZY, 2005). The institution of beitianfangs profoundly influenced Chinese Buddhist charity, with some of them continuing down to the present. For example, recently Shaolin Temple reopened their charitable medicinal store called Shaolin Yaoju, which is generally regarded as a "modern beitianfang" . However, in the event of emergencies, the pharmacist-monks of Shaolin Temple take part in medical charity (Zhong, 2008). It is worth mentioning that some travelling pharmacist-monks independent from temples also used Chinese herbal medicines to cure diseases for patients. For example, the poet Cao Song who was suffering from "cold syndrome" became well soon after taking medicine from an unknown travelling monk. In his poem, he expressed his appreciation to the monk (Cao S, 1960b).

In addition, pharmacist-monks provided (functional) food for devotees at Buddhist temples. Of course, some of herbal medicines can also be consumed as food. Yuzhu (Jiao, 1960a; Cao Z, 1960) is a typical example, in which there are a lot 
of dietary ingredients such as sugars and polyphenolics, and it can be eaten as food even today. In a poem of Bai Juyi, the poet says that he ate dietary herbal medicines for breakfast with monks in a temple (Bai, 1960h). Another poet, Han Hong, described monks eating the tender leaves of medicinal plants for dinner, during which the master taught the Buddhist philosophy of anutpada-jnana using tender leaves as model (Han H, 1960).

Finally, pharmacist-monks also beautified the temple and improved their environments. Our inspection suggested that there are 16 flowers and 6 leaves in the herbal medicines planted by pharmacist-monks. Among them, lotuses and lotus leaves are very popular (Bai, 1960a; Bai, 1960b; Bai, 1960d; Du, 1960b; Ding, 1960; Pei, 1960; Wei, 1960; Zhao, 1960), which can partly be attributed to the lotus being a Buddhist symbol; pharmacist-monks were therefore inclined to plant them in front of temples. Some flowers however could yield volatile oils, and therefore smelled sweet. Their scent could alter a person's mind, mood, cognitive function or health (Charles, 2003). This obviously was beneficial for not only the health of Buddhist monks, but Buddhist learning and practice as well.

Apparently, all these contributions of pharmacist-monks however are considered as dana paramita. It is dharma dana to teach Buddhist philosophy with yatha-pratyata and it is fearlessness dana to directly carry out the medical charity to relieve the sufferings of sentient being. To provide herbal medicines and food is involved in fearlessness dana and property dana. To beautify the temple and improve their environments, however, may include property dana, dharma dana, and fearlessness dana.

\subsubsection{Sila-vinaya Paramita}

Sila means "abstentions" or prohibition against misdeed; while vinaya means religious "discipline" (Chen B, 1993b). Therefore, sila-vinaya means Buddhist precepts in Sanskrit. Our inspection revealed that no record of animal-derived ingredients is found in more than 70 poems related to pharmacist-monks in the Tang Dynasty (Peng, Dingqiu et al. 1960). It implies that pharmacist-monks followed the precept of Ahimsa (non-harming or nonviolence) in mahayana Buddhism, since taking animal-derived ingredients requires slaughtering and shedding of blood (Tan, 2014). It suggests that they followed sila-vinaya paramita.

\subsubsection{Ksanti Paramita}

Ksanti is patience, tolerance, forbearance, endurance, or composure (Chen B, 1993c). As can be seen in the above, the production process of herbal medicines was toilsome and laborious. Nevertheless, Yuanda, an old pharmacist-monk aged over 80 years, enjoyed cultivating medicinal plants. According to the poem by Pi Rixiu (Pi, 1960a) (Figure 2B), he often labored in his medicinal garden to plant and water medicinal herbs, including baizhu, guizhi, diaohu, shaoyao, and so on. Sometimes he carefully collected, washed, and identified various kinds of Chinese herbal medicine. The medicinal plants he cultivated were colorful and beautiful. Thereby, Yuanda is described as an expert in the cultivation of medicinal plants. Undoubtedly, his work was laborious; nevertheless, he felt happy and was free from vulgarity ( $\mathrm{Pi}$, 1960a). This is because he followed ksanti paramita. As discussed above, other manufacturing processes were also laborious even dangerous, such as searching for herbal medicines around the mountain (Li D, 1960b; Jiao, 1960c) and sun-drying of herbal medicines in shaiyaotai in a mountain (Bai, 1960a). This was also a kind of ksanti paramita.

\subsubsection{Virya Paramita}

Virya can be defined as an attitude of gladly engaging in wholesome activities, and it functions to cause one to accomplish wholesome or virtuous actions (Chen B, 1993b). A typical example is old pharmacist-monk named Hongshi. In accordance with the record by Wang Jian (Wang J, 1960b), Hongshi often kindly donated the medicine to the people in need. However, if more medicines were required, he was glad to continue to search for wild (medicinal) plants for people, regardless of age and toil. This is a kind of virya paramita. The original intention is to relieve the suffering of sentient beings, then to guide people to come to Buddha. His ethical action that he never abandoned secular society. This is the core of mahayana Buddhism. In Sanskrit, mahayana literally means "great vehicle" which can not only carry oneself but also the other to the destination (becoming Buddha). Hence, these pharmacist-monks living in forests or mountains far from secular society, are actually mahayana followers (not hinayana followers).

\subsubsection{Dhyana and Prajna Paramitas}

Dhyana usually means "meditation", Buddhist meditation is a discipline intended to cultivate the mind. It can lead to state of perfect equanimity and awareness (Chen B, 1993d). In mahayana Buddhism, it is an essential religious practice. In Poetry of the Tang Dynasty, we found several records concerning dhyana practice of pharmacist-monk. An old pharmacist-monk, for example, was observed to sit cross legged to practice dhyana in front of a medicinal plant (Guizhi) of Fahua Temple on a mountain (Jiao, 1960b). It must be noted that meditation with sitting cross legged is pre-convenience of dhyana-practicing, not dhyana itself (Shi, 2014). However, dhyana-practicing is helpful to reach prajna, which is spoken of as the principal means of attaining nirvana, through its revelation of the true nature of all things as sunyata (emptiness) (Chen B, 1993c). A mahayana follower awakening and realizing sunyata may get rid of 
illusionary pain from secular affairs. Therefore, as a group of mahayana followers, the pharmacist-monks in the Tang Dynasty lived happily and free from vulgarity, despite their laborious cultivation activities. Yuanda mentioned above is a typical example.

In summary, from the samvrti-satya viewpoint, these pharmacist-monks devoted themselves to the production of Chinese herbal medicines. However, from the paramartha-satya viewpoint, they were engaged in six paramitas practice. The fulfillment of six paramitas made the pharmacist-monks be widely respected by the secular society in the Tang Dynasty. Some secular patients suffering from various diseases preferred to seek treatment at Buddhist temples (Chen T, 1960). The poet Wang Jiang also once intended to visit pharmacist-monks on account of their medicine being cheaper (Wang J, 1960c). The famous poet Cen Shen (Cen, 1960b) even described pharmacist-monks as Bhaisajya-rāja Bodhisattva (the Buddha of Healing) of the Lotus Sutra (Figure 5) (Gautama, 2000), who usually kindly donates medicine to all sentient beings to help assuage their experiences of suffering in saha world. Obviously, their ethical actions inherited mahayanist tradition which might start in Dharmaraksa (AD. 231-308) period (Jiang, 2011), and accelerated the development of mahayana Buddhism in China.
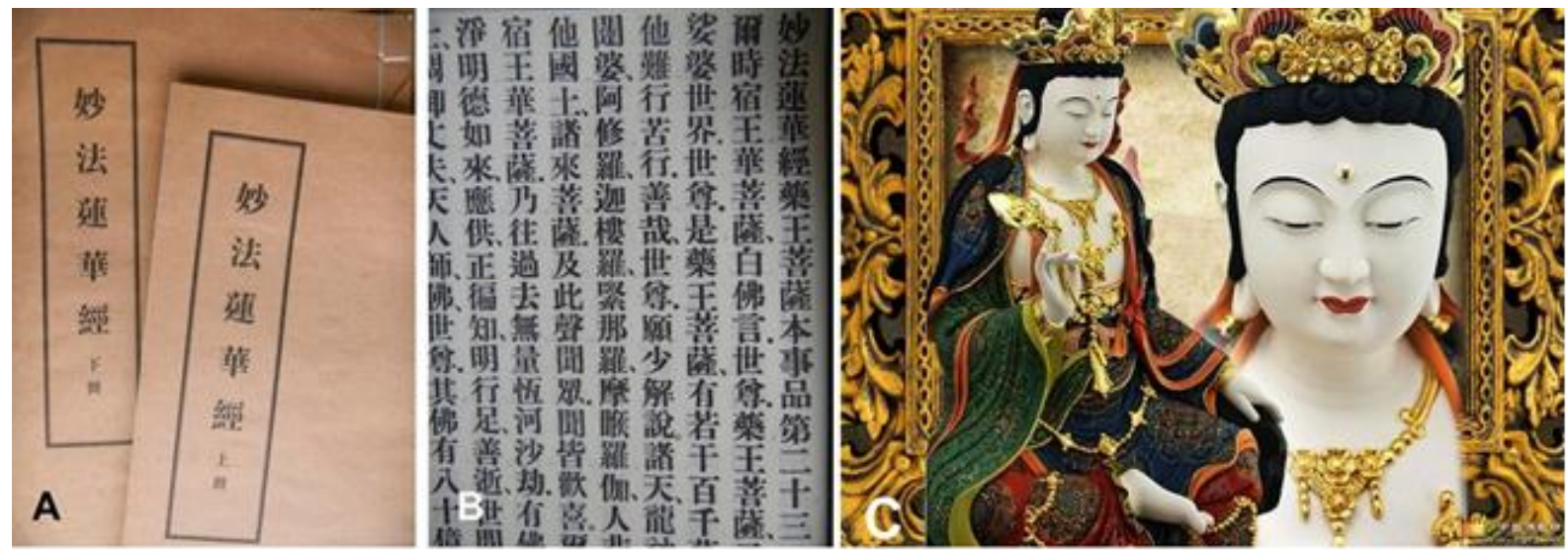

Figure 5. The Lotus Sutra (A), description of the Bhaisajya-rāja Bodhisattva (the Buddha of Healing, B) and statue of the Medicine King Bodhisattva (C) (A and B are contributed by Xican Li; C is contributed by www.zgfj.cn)

\section{Conclusion}

In conclusion, our analysis has demonstrated that there were numerous pharmacist-monks (yaoseng) in the Tang Dynasty in China. As a group of mahayana followers, these pharmacist-monks participated in the entire manufacturing process for Chinese herbal medicines. They provided herbal medicines as a form of Chinese Buddhism charity and food for devotees at Buddhist temples. Sometimes they directly took part in medical charity activity to express compassionate ideals of Buddhism. In addition, they beautified Buddhist temples. Because of their religious practice of six paramitas (including dana, sila-vinaya, ksanti, virya, dhyana, and prajna), they lived laborious but happy, and had been widely respected by the Chinese in the Tang Dynasty. They inherited mahayanist tradition and accelerated the development of mahayana Buddhism in China.

\section{Conflicts of Interest}

The authors declare no conflict of interest.

\section{References}

Bai, J. Y. (1960a). The poems of Bai Juyi. In Poetry of Tang Dynasty, D.Q. Peng, et al (Eds), Beijing: Zhonghua Book Company, 429, 4734.

Bai, J. Y. (1960b). The poems of Bai Juyi. In Poetry of Tang Dynasty, D.Q. Peng, et al (Eds), Beijing: Zhonghua Book Company, 441, 4917.

Bai, J. Y. (1960c). The poems of Bai Juyi. In Poetry of Tang Dynasty, D.Q. Peng, et al (Eds), Beijing: Zhonghua Book Company, 432, 4768.

Bai, J. Y. (1960d). The poems of Bai Juyi. In Poetry of Tang Dynasty, D.Q. Peng, et al (Eds), Beijing: Zhonghua Book Company, 441, 4915.

Bai, J. Y. (1960e). The poems of Bai Juyi. In Poetry of Tang Dynasty, D.Q. Peng, et al (Eds), Beijing: Zhonghua Book Company, 443, 4958. 
Bai, J. Y. (1960f). The poems of Bai Juyi. In Poetry of Tang Dynasty, D.Q. Peng, et al (Eds), Beijing: Zhonghua Book Company, 443, 4957.

Bai, J. Y. (1960g). The poems of Bai Juyi. In Poetry of Tang Dynasty, D.Q. Peng, et al (Eds), Beijing: Zhonghua Book Company, 449, 5062.

Bai, J. Y. (1960h). The poems of Bai Juyi. In Poetry of Tang Dynasty, Edited by Peng Dingqiu et al. Beijing: Zhonghua Book Company, 439, 4891.

Cao, Z. (1960). The poems of Cao Zhu. In Poetry of Tang Dynasty, D.Q. Peng, et al (Eds), Beijing: Zhonghua Book Company, 466, 5298.

Cao, S. (1960a). The poems of Cao Song. In Poetry of Tang Dynasty, D.Q. Peng, et al (Eds), Beijing: Zhonghua Book Company, 716, 8229.

Cao, S. (1960b). The poems of Cao Song. In Poetry of Tang Dynasty, Edited by Peng Dingqiu et al. Beijing: Zhonghua Book Company, 716, 8228-8229.

Cen, S. (1960a). The poems of Cen Shen. In Poetry of Tang Dynasty, D.Q. Peng, et al (Eds), Beijing: Zhonghua Book Company, 201, 2097.

Cen, S. (1960b). The poems of Cen Shen. In Poetry of Tang Dynasty, D.Q. Peng, et al (Eds), Beijing: Zhonghua Book Company, 200, 2092.

Charles, R., Lewis, A. D. V., Barbara R. R. S., and Christina, T. (2003). Integrating complementary and alternative medicine (CAM) into standard hospice and palliative care. American Journal Hospital Palliat Care, 20, 221-228. http://dx.doi.org/10.1177/104990910302000312

Chen, B. (1993a). New dictionary of Buddhism. Chinese Esperanto Publishing House, Beijing, China, 141.

Chen, B. (1993b). New Dictionary of Buddhism. Chinese Esperanto Publishing House, Beijing, China, 60.

Chen, B. (1993c). New Dictionary of Buddhism. Chinese Esperanto Publishing House, Beijing, China, 151

Chen, B. (1993d). New Dictionary of Buddhism. Chinese Esperanto Publishing House, Beijing, China, 152.

Chen, T. (1960). The poems of Chen Tao. In Poetry of Tang Dynasty, D.Q. Peng, et al (Eds), Beijing: Zhonghua Book Company, 746, 8488.

Ding, X. Z. (1960). The poems of Ding Xianzhi. In Poetry of Tang Dynasty, D.Q. Peng, et al (Eds), Beijing: Zhonghua Book Company, 114, 1155.

Du, F. (1960a). The poems of Du Fu. In Poetry of Tang Dynasty, D.Q. Peng, et al (Eds), Beijing: Zhonghua Book Company, 218, 2289.

Du, F. (1960b). The poems of Du Fu. In Poetry of Tang Dynasty, D.Q. Peng, et al (Eds), Beijing: Zhonghua Book Company, 225, 2419.

Duan, Y. Z. (1960). The poems of Wang Jian. In Poetry of Tang Dynasty, D.Q. Peng, et al (Eds), Beijing: Zhonghua Book Company, 795, 8962.

Gautama, S. (2000). The Lotus Sutra. Zhejiang: Tiantaishan Guoqing Temple, 495.

Gu, K. (1960). The poems of Gu Kuang. In Poetry of Tang Dynasty, D.Q. Peng, et al (Eds), Beijing: Zhonghua Book Company, 883, 9976.

Guan, X. (1960). The poems of Guan Xiu. In Poetry of Tang Dynasty, D.Q. Peng, et al (Eds), Beijing: Zhonghua Book Company, 832, 9391.

Han, H. (1960). The poems of Han Hong. In Poetry of Tang Dynasty, Edited by Peng Dingqiu et al. Beijing: Zhonghua Book Company, 244, 2738.

Han, Y. (1960). The poems of Han Yu. In Poetry of Tang Dynasty, D.Q. Peng, et al (Eds), Beijing: Zhonghua Book Company, 338, 3791.

Harold, G. K. (2012). Religion, Spirituality, and Health: The Research and Clinical Implications. International Scholarly Research Network, ISRN Psychiatry, Article ID 278730, 33, http://dx.doi.org/10.5402/2012/278730.

Huangfu R. (1960). The poems of Huangfu Ran. In Poetry of Tang Dynasty, D.Q. Peng, et al (Eds), Beijing: Zhonghua Book Company, 249, 2809.

Huangfu Z. (1960). The poems of Huangfu Zeng. In Poetry of Tang Dynasty, D.Q. Peng, et al (Eds), Beijing: Zhonghua Book Company, 210, 2184. 
Jia, D. (1960). The poems of Jia Dao. In Poetry of Tang Dynasty, D.Q. Peng, et al (Eds), Beijing: Zhonghua Book Company, 573, 6672.

Jiang, W. Q. (2011). History of Chinese Buddhism. Shanghai: Shanghai Classics Publishing Press, 11, 86

Jiao, R. (1960a). The poems of Jiao Ran. In Poetry of Tang Dynasty, D.Q. Peng, et al (Eds), Beijing: Zhonghua Book Company, 818, 9224.

Jiao, R. (1960b). The poems of Jiao Ran. In Poetry of Tang Dynasty, D.Q. Peng, et al (Eds), Beijing: Zhonghua Book Company, 817, 9210.

Jiao, R. (1960c). The poems of Jiao Ran. In Poetry of Tang Dynasty, Edited by Peng Dingqiu et al. Beijing: Zhonghua Book Company, 819, 9227.

Jin, J. Q. (2015). The poems of Jin Junqing. In Poetry of Song Dynasty.

Li, B. (1960). The poems of Li Bai. In Poetry of Tang Dynasty, D.Q. Peng, et al (Eds), Beijing: Zhonghua Book Company, 177, 1804.

Li, D. (1960). The poems of Li Duan. In Poetry of Tang Dynasty, Edited by Peng Dingqiu et al. Beijing: Zhonghua Book Company, 285, 3264.

Li, D. Y. (1960). The poems of Li Deyu. In Poetry of Tang Dynasty, D.Q. Peng, et al (Eds), Beijing: Zhonghua Book Company, 475, 5400.

Li, X. (1960). The poems of Li Xin. In Poetry of Tang Dynasty, D.Q. Peng, et al (Eds), Beijing: Zhonghua Book Company, 132, 1347.

Li, X. Y. (1960). The poems of Li Xianyong. In Poetry of Tang Dynasty, D.Q. Peng, et al (Eds), Beijing: Zhonghua Book Company, 646, 7415.

Li, Y. X. (1960). The poems of Liu Yuxi. In Poetry of Tang Dynasty, D.Q. Peng, et al (Eds), Beijing: Zhonghua Book Company, 360, 4061.

Liu, J. (1960). The poems of Liu Jian. In Poetry of Tang Dynasty, D.Q. Peng, et al (Eds), Beijing: Zhonghua Book Company, 766, 8698.

Liu, S. (1960a). The poems of Liu Shang. In Poetry of Tang Dynasty, D.Q. Peng, et al (Eds), Beijing: Zhonghua Book Company, 304, 3457.

Liu, S. (1960b). The poems of Liu Shang. In Poetry of Tang Dynasty, D.Q. Peng, et al (Eds), Beijing: Zhonghua Book Company, 304, 3458.

Liu, X. (2015a). The Old Book of Tang History, 16. http://www.guoxue.com/shibu/24shi/oldtangsu/jts_016.htm (accessed on 10 July, 2015).

Liu, X. (2015b). The Old Book of Tang History, 184. http://www.guoxue.com/shibu/24shi/oldtangsu/jts_188.htm (accessed on 10 July, 2015)

Liu, Y. S. (1960). The poems of Liu Yanshi. In Poetry of Tang Dynasty, D.Q. Peng, et al (Eds), Beijing: Zhonghua Book Company, 468, 5328.

Lu, G. M. (1960). The poems of Lu Guimeng. In Poetry of Tang Dynasty, D.Q. Peng, et al (Eds), Beijing: Zhonghua Book Company, 625, 7183.

Pei, D. (1960). The poems of Pei Du. In Poetry of Tang Dynasty, D.Q. Peng, et al (Eds), Beijing: Zhonghua Book Company, 335, 3755.

Pi, R. X. (1960a). The poems of Pi Rixiu. In Poetry of Tang Dynasty, D.Q. Peng, et al (Eds), Beijing: Zhonghua Book Company, 613, 7078.

Pi, R. X. (1960b). The poems of Pi Rixiu. In Poetry of Tang Dynasty, D.Q. Peng, et al (Eds), Beijing: Zhonghua Book Company, 615, 7097.

Qi, J. (1960). The poems of Qi Ji. In Poetry of Tang Dynasty, D.Q. Peng, et al (Eds), Beijing: Zhonghua Book Company, $839,9466$.

Quan, D. Y. (1960). The poems of Quan Deyu. In Poetry of Tang Dynasty, D.Q. Peng, et al (Eds), Beijing: Zhonghua Book Company, 327, 3664.

Shi, H. J. (1992). The Biography of Eminent Monks (Liang). Beijing: Zhonghua Book Company, 4-8.

Shi, H. N. (2014). Platform Sutra of the Sixth Patriarch. Guangzhou: Liurong Temple, 31-50. 
Si, K. S. (1960). The poems of Si Kongshu. In Poetry of Tang Dynasty, D.Q. Peng, et al (Eds), Beijing: Zhonghua Book Company, 292, 3314.

Sun, F. (1960). The poems of Sun Fang. In Poetry of Tang Dynasty, D.Q. Peng, et al (Eds), Beijing: Zhonghua Book Company, 886, 10017.

Tan, M. M., Carina, K. Y., Chan, and Daniel, D. R. (2014). Faith, Food and Fettle: Is Individual and Neighborhood Religiosity/Spirituality Associated with a Better Diet? Religions, 5, 801-813. http://dx.doi.org/10.3390/rel5030801

Wang, J. (1960a). The poems of Wang Jian. In Poetry of Tang Dynasty, D.Q. Peng, et al (Eds), Beijing: Zhonghua Book Company, 300, 3402.

Wang, J. (1960b). The poems of Wang Jian. In Poetry of Tang Dynasty, Edited by Peng Dingqiu et al. Beijing: Zhonghua Book Company, 299, 3396.

Wang, J. (1960c). The poems of Wang Jian. In Poetry of Tang Dynasty, D.Q. Peng, et al (Eds), Beijing: Zhonghua Book Company, 299, 3394.

Wang, W. (1960). The poems of Wang Wei. In Poetry of Tang Dynasty, D.Q. Peng, et al (Eds), Beijing: Zhonghua Book Company, 125, 1241.

Wei, Y. W. (1960). The poems of Wei Yingwu. In Poetry of Tang Dynasty, D.Q. Peng, et al (Eds), Beijing: Zhonghua Book Company, 193, 1994.

Wu, K. (1960). The poems of Wu Ke. In Poetry of Tang Dynasty, D.Q. Peng, et al (Eds), Beijing: Zhonghua Book Company, 813, 9151.

Xiang, S. (1960). The poems of Xiang Si. In Poetry of Tang Dynasty, D.Q. Peng, et al (Eds), Beijing: Zhonghua Book Company, 554, 6421.

Xu, H. (1960). The poems of Xu Hun. In Poetry of Tang Dynasty, D.Q. Peng, et al (Eds), Beijing: Zhonghua Book Company, 538, 6140.

Xu, Y. (1960a). The poems of Xu Yin. In Poetry of Tang Dynasty, D.Q. Peng, et al (Eds), Beijing: Zhonghua Book Company, 709, 8164.

Xu, Y. (1960b). The poems of Xu Yin. In Poetry of Tang Dynasty, D.Q. Peng, et al (Eds), Beijing: Zhonghua Book Company, 709, 8165.

Xu, Z. Y. (1960). The poems of Xu Zhongya. In Poetry of Tang Dynasty, D.Q. Peng, et al (Eds), Beijing: Zhonghua Book Company, 762, 8650.

Xue, N. (1960a). The poems of Xue Neng. In Poetry of Tang Dynasty, D.Q. Peng, et al (Eds), Beijing: Zhonghua Book Company, 560, 6494.

Xue, N. (1960b). The poems of Xue Neng. In Poetry of Tang Dynasty, D.Q. Peng, et al (Eds), Beijing: Zhonghua Book Company, 560, 6506.

Yao, H. (1960). The poems of Xu Zhongya. In Poetry of Tang Dynasty, D.Q. Peng, et al (Eds), Beijing: Zhonghua Book Company, 501, 5694.

Yu, H. (1960). The poems of Yu Hu. In Poetry of Tang Dynasty, Edited by Peng Dingqiu et al. Beijing: Zhonghua Book Company, 310, 3500 .

Yuan, Z. (1960a). The poems of Yuan Zhen. In Poetry of Tang Dynasty, D.Q. Peng, et al (Eds), Beijing: Zhonghua Book Company, 403, 4506.

Yuan, Z. (1960b). The poems of Yuan Zhen. In Poetry of Tang Dynasty, D.Q. Peng, et al (Eds), eds.; Beijing: Zhonghua Book Company, 408, 4541.

Zan, N. (1987a). The Biography of Eminent Monks (Song Dynasty). Beijing: Zhonghua Book Company, 24, 613.

Zan, N. (1987b). The Biography of Eminent Monks (Song Dynasty). Beijing: Zhonghua Book Company, 22, 448.

Zan, N. (1987c). The Biography of Eminent Monks (Song Dynasty). Beijing: Zhonghua Book Company, 26, 669.

Zhang, J. (1960). The poems of Zhang Ji. In Poetry of Tang Dynasty, D.Q. Peng, et al (Eds), Beijing: Zhonghua Book Company, 386, 4360.

Zhang, Z. Y. (2005). Study on the Beitianfang in Tang Dynasty. Qinghai Social Sciences, 2,106-109.

Zhao, G. (1960). The poems of Zhao Gu. In Poetry of Tang Dynasty, D.Q. Peng, et al (Eds), Beijing: Zhonghua Book Company, 549, 6350. 
Zhong, Y. (2008). 10 Yaoseng (pharmacist-monks) from Shaolin Temple were sent to Wenchuan disaster area to save the injured people and to develop traditional Chinese medicine. Journal of Chinese Medicine Modern Distance Education of China, 6, 57.

Zhou, H. (1960). The poems of Zhou He. In Poetry of Tang Dynasty, D.Q. Peng, et al (Eds), Beijing: Zhonghua Book Company, 503, 5724.

Zhou, H. L. (1960). The poems of Zhou Hongliang. In Poetry of Tang Dynasty, D.Q. Peng, et al (Eds), Beijing: Zhonghua Book Company, 466, 5298.

\section{(cc) $\mathrm{BY}$}

This work is licensed under a Creative Commons Attribution 3.0 License. 